\title{
Illuminating the role of cholinergic signaling in circuits of attention and emotionally salient behaviors
}

\author{
Antonio Luchicchi' ${ }^{1}$, Bernard Bloem ${ }^{1,2}$, John Noel M. Viaña ${ }^{1}$, Huibert D. Mansvelder ${ }^{*}$ and Lorna W. Role ${ }^{3}$ \\ Department of Integrative Neurophysiology, Center for Neurogenomics and Cognitive Research, Neuroscience Campus Amsterdam, Vrije Universiteit, \\ Amsterdam, Netherlands \\ ${ }^{2}$ McGovern Institute for Brain Research, Massachusetts Institute of Technology, Cambridge, MA, USA \\ ${ }^{3}$ Department of Neurobiology and Behavior, Stony Brook University, Stony Brook, NY, USA
}

\author{
Edited by: \\ Sukumar Vijayaraghavan, University \\ of Colorado Health Science Center, \\ USA

\section{Reviewed by:} \\ Dan McGehee, University of \\ Chicago, USA \\ John A. Dani, Baylor College of \\ Medicine, USA

\section{*Correspondence:} \\ Huibert D. Mansvelder, Department \\ of Integrative Neurophysiology, \\ Center for Neurogenomics and \\ Cognitive Research, Neuroscience \\ Campus Amsterdam, Vrije \\ Universiteit, de Boelelaan 1085, \\ 1081 HV, Amsterdam, Netherlands \\ e-mail: h.d.mansvelder@vu.nl; \\ Lorna W. Role, Department of \\ Neurobiology and Behavior, Stony \\ Brook University, Stony Brook, NY \\ 11794, USA \\ e-mail: Iorna.role@stonybrook.edu
}

Acetylcholine (ACh) signaling underlies specific aspects of cognitive functions and behaviors, including attention, learning, memory and motivation. Alterations in ACh signaling are involved in the pathophysiology of multiple neuropsychiatric disorders. In the central nervous system, ACh transmission is mainly guaranteed by dense innervation of select cortical and subcortical regions from disperse groups of cholinergic neurons within the basal forebrain (BF; e.g., diagonal band, medial septal, nucleus basalis) and the pontine-mesencephalic nuclei, respectively. Despite the fundamental role of cholinergic signaling in the CNS and the long standing knowledge of the organization of cholinergic circuitry, remarkably little is known about precisely how ACh release modulates cortical and subcortical neural activity and the behaviors these circuits subserve. Growing interest in cholinergic signaling in the CNS focuses on the mechanism(s) of action by which endogenously released ACh regulates cognitive functions, acting as a neuromodulator and/or as a direct transmitter via nicotinic and muscarinic receptors. The development of optogenetic techniques has provided a valuable toolbox with which we can address these questions, as it allows the selective manipulation of the excitability of cholinergic inputs to the diverse array of cholinergic target fields within cortical and subcortical domains. Here, we review recent papers that use the light-sensitive opsins in the cholinergic system to elucidate the role of ACh in circuits related to attention and emotionally salient behaviors. In particular, we highlight recent optogenetic studies which have tried to disentangle the precise role of ACh in the modulation of cortical-, hippocampal- and striatal-dependent functions.

Keywords: acetylcholine, optogenetics, nicotinic receptors, limbic circuitries, attention

\section{INTRODUCTION}

Acetylcholine (ACh) is essential to normal CNS function, modulating cognitive, emotional and behavioral functions, including learning and memory (Kilgard and Merzenich, 1998; Hasselmo and Giocomo, 2006), reward (Leslie et al., 2013), wakefulness and attention (Klinkenberg et al., 2011; see Picciotto et al., 2012 for a recent review). Appropriate levels of ACh are required to process relevant sensory information and for encoding environmental cues that drive goal-directed behavior (Sarter et al., 2009). Disruptions of cholinergic transmission contribute to the pathophysiology of neuropsychiatric disorders, including Alzheimer's disease, schizophrenia and drug addiction (Court et al., 2001; Dani and Harris, 2005; Martin and Freedman, 2007). To support its prominent role in the brain, the cholinergic system sends dense projections from sparse cholinergic nuclei, that include the basal forebrain $(\mathrm{BF})$, laterodorsal tegmental nucleus (LDTg), peduculopontine tegmentum (PPTg), and medial habenula (MHb; Woolf, 1991; Mesulam, 1995; Zaborszky et al., 1999; Ren et al., 2011). In addition, there is a small population of choline acetyltransferase (ChAT) positive interneurons in areas including the striatum and neocortex (Woolf, 1991; Mesulam, 1995; von Engelhardt et al., 2007). Cholinergic projections, from the BF, LDTg and PPTg nuclei extend throughout the main telencephalic and limbic structures delivering ACh to broad terminal fields. Released ACh activates via both ionotropic nicotinic and metabotropic muscarinic ACh receptors (nAChRs, and mAChRs, respectively) that vary in terms of cellular localization (pre- and/or postsynaptic), subunit composition, signaling mechanism(s) and affinity for ACh (for recent reviews see Wess, 2003; Gotti and Clementi, 2004; Changeux, 2010; Picciotto et al., 2012).

Although our understanding of the organization of the cholinergic system and its role in modulating certain behaviors is growing, many questions remain to be answered to understand the dynamics of ACh action and its involvement in (patho) physiology. The role of ACh in specific behaviors has been addressed using lesions of cholinergic projections or pharmacological interventions with ACh receptor activation. Such approaches, though informative, are confounded by issues of bioavailability, lack of complete reversibility and the fact that such interventions act on time scales of unknown relevance for cholinergic driven changes 
in excitability in vivo. Our understanding of how cholinergic projections innervate and modulate target circuitry remains rudimentary. In fact, it is not even clear whether ACh acts as a classic synaptic neurotransmitter-on the millisecond to tens of millisecond time scale-or whether it acts as a neuromodulator (at the hundreds of milliseconds to seconds time scale) or both (see Picciotto et al., 2012; Sarter et al., 2014). The latter hypothesis is supported by several investigations that emphasize the predominant role of ACh in modifying cell excitability and activity of entire networks of neurons (Wonnacott, 1997; Kawai et al., 2007). Moreover, a relatively modest specificity of the cholinergic system exists in terms of connectivity in crucial target regions such as the cortex (see Sarter et al., 2009, for a review). On the other hand, the presence of point-to-point sites of ACh release juxtaposed to cholinergic receptors suggests that the cholinergic system may also utilize fast synaptic signaling, typical of classic neurotransmitters (Smiley et al., 1997; Turrini et al., 2001). Indeed, the complexity of results obtained to date has led to the conclusion that ACh signaling may occur over a range of different time courses due, in part, to varied release mechanisms and proximity of release and receptive sites as well as to the involvement of distinct signaling cascades downstream of both nicotinic and muscarinic AChRs (e.g see Arroyo et al., 2014; Jiang et al., 2014). A lack of hightemporal resolution and accurate detection methods for ACh release has hampered our understanding of whether endogenous cholinergic signaling is mediated by rapid, transient release (millisecond time-scale) and/or by a more diffuse transmission (from second to minute time-scale).

With the exponential rise in the number and type of optogenetic tools developed over the last decade it is now possible to selectively stimulate or inhibit specific populations of CNS cholinergic neurons and/or their axonal terminal fields through the activation of light-sensitive opsins (for reviews see: Deisseroth, 2011; Yizhar et al., 2011; Poorthuis et al., 2014). Here, we review the recent studies that have used the expression of photo-sensitive opsins in the cholinergic system to elucidate the role of endogenous ACh signaling in different brain regions related to attention and emotionally salient/ limbic behaviors.

\section{BASAL FOREBRAIN ACH AND NEOCORTICAL FUNCTION}

The mechanisms by which ACh release in the neocortex influences cognitive functions and behaviors are still poorly understood. While early microdialysis studies in the medial prefrontal cortex (mPFC) reported a long-lasting ACh increase during attention-related performance tasks (Passetti et al., 2000), more recent works with faster, dynamic, electrochemical detection of choline, have shown that ACh can also be released briefly in concert with cue detection in a cued appetitive response task (Parikh et al., 2007; Parikh and Sarter, 2008). Thus, while the microdialysis assays are consistent with the idea that ACh release could promote a general state of cortical arousal, due to sustained levels of ACh over long time-scales, recent and more sensitive electrochemical assays highlight a faster, and more transient release of ACh. The latter observation modifies the prior view that ACh only acts through "volume transmission" (Sarter et al., 2009), and underscores the possibility of faster components of ACh action in the modulation of specific cholinergic functions. For example, the phasic release of ACh would support more rapid transitions of cortical states, consistent with cholinergic regulation of an animal's ability to incorporate the detection of a cue into new goal-directed behaviors (Sarter et al., 2014).

\section{CHOLINERGIC FAST SYNAPTIC TRANSMISSION IN CORTEX}

The application of optogenetic tools to the analysis of central cholinergic signaling using ChAT-Cre lines in either mice (Kalmbach et al., 2012; Huang and Zeng, 2013) or rats (Witten et al., 2011; see Figure 1) allows selective activation and silencing of cholinergic neurons and axonal projections, both in vitro and in vivo. Using this approach, several studies have now shown that ACh signaling occurs through direct, fast synaptic transmissionas well as over longer time scales consistent with more diffuse transmission-in the cortex (Letzkus et al., 2011; Arroyo et al., 2012, 2014; Bennett et al., 2012; Kimura et al., 2014). Activating channelrhodopsin (ChR2) in fibers from the BF elicited a barrage of inhibitory synaptic inputs to layer (L) 2/3 pyramidal cells, which depended on $\mathrm{nAChR}$ activation (Arroyo et al., 2012, 2014; Bennett et al., 2012; Kimura et al., 2014). Pyramidal neurons in L2/3 apparently do not express nAChRs themselves, but L2/3 interneurons do (Poorthuis et al., 2013). Activation of BF fibers produced cell type-specific responses in cortical interneurons. L1 and L2/3 LS neurons exhibited both a fast and a slow response, while L2/3 ChAT bipolar neurons exhibited only a slow response. Activation of $\mathrm{L} 2 / 3$ interneurons by $\mathrm{ACh}$ via both nicotinic and muscarinic receptors depressed pyramidal neuron firing thereby curtailing visual responses (Kimura et al., 2014). ACh-induced excitatory postsynaptic currents were generated by a mixed population of nAChRs (Arroyo et al., 2012). In addition to a slow dihydro- $\beta$-erythroidine (DH $\beta E$ ) sensitive non- $\alpha 7^{*}$-mediated current, a fast component of excitatory postsynaptic potentials (EPSCs) was abolished by methyllycaconitine (MLA) in both L1 and 2/3 interneurons but not in ChAT+ cells. Comparing the reported time course of the inhibitory barrage received by $\mathrm{L} 2 / 3$ pyramidal neurons upon light-induced ACh release with the time course of the two different EPSC components, suggested that $\mathrm{L} 2 / 3$ pyramidal neuron inhibition is more likely dependent on the slow component, rather than the fast component of cholinergic activation. This was confirmed by bath application of $\mathrm{Dh} \beta \mathrm{E}$, which prevented the inhibitory drive onto pyramidal cells. In a follow-up study, the same authors found a large trial-to trial variability of the fast component of the ACh-induced current components, indicative of direct synaptic transmission which they propose is mediated by synaptic $\alpha 7^{*}$ containing $\left(\alpha 7^{*}\right)$ receptors. This was confirmed by lack of effect of AChE inhibitors on the amplitude or kinetics of this fast current component (Bennett et al., 2012; Arroyo et al., 2014). The slow component showed much less trial-to-trial variability and was sensitive to manipulation of AChE activity. From this, the authors conclude that the slow, non- $\alpha 7^{*}$ component involves diffusion of ACh over some distance, and arises from the effects of ACh on extra synaptic $\alpha 4 \beta 2 *$ nAChRs, while the faster nAChR EPSCs are mediated by direct transmission via synaptic or peri-synaptic $\alpha 7^{*}$ AChRs (Arroyo et al., 2012, 2014). These experiments demonstrate that in superficial layers of the somatosensory, visual and auditory cortex, $\mathrm{L} 1$ and $\mathrm{L} 2 / 3$ interneurons receive both direct and 


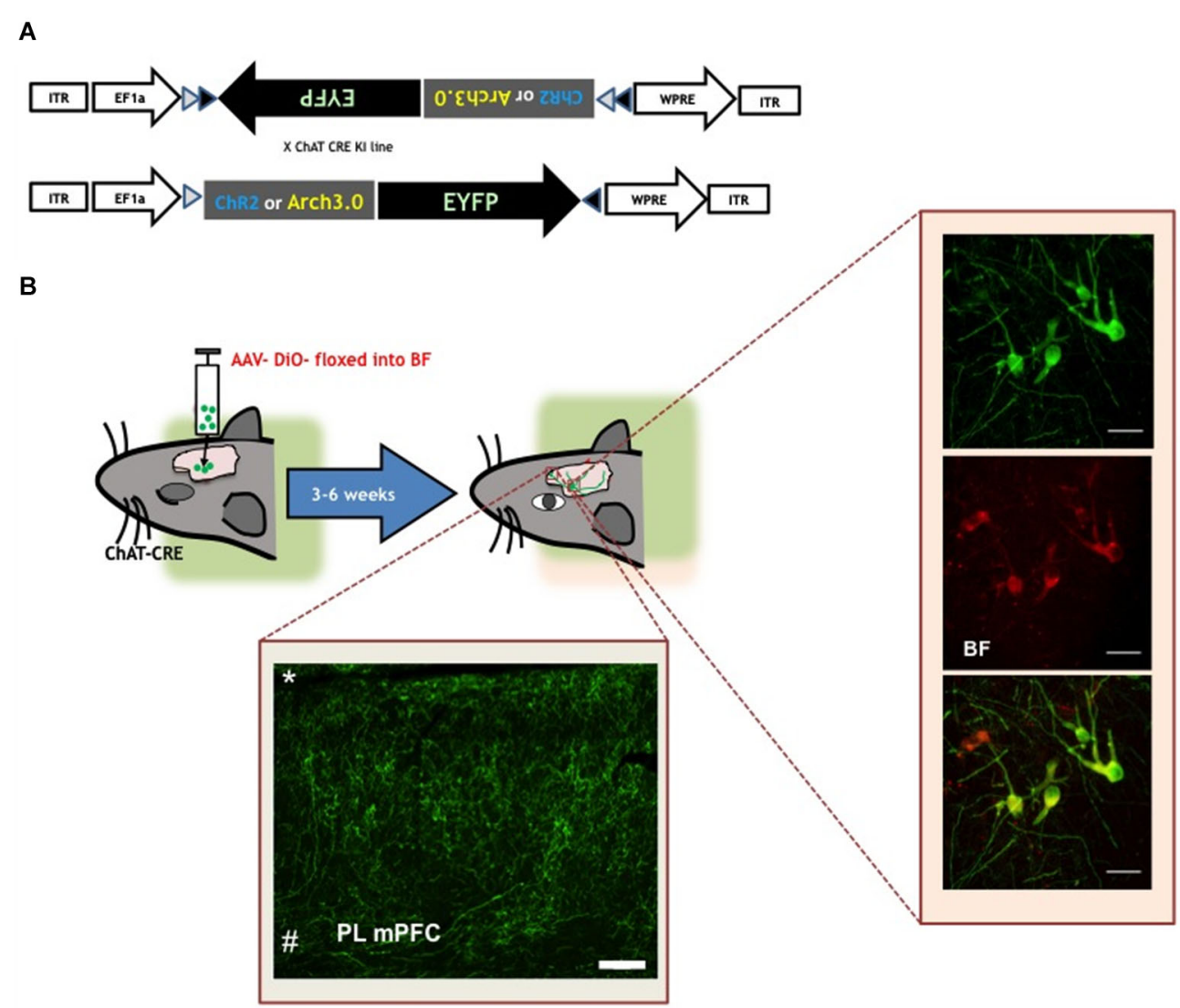

FIGURE 1 | Visualizing the cholinergic system in rodents. (A) Viral construct used to achieve selective expression of functional opsins (ChR2 or Arch3.0) in ChAT+ cells (Witten et al., 2011). Top panel shows the construct that is sterotactically injected in the basal forebrain region of ChAT-cre mice or rats. The portion of the construct encoding the opsin and fluorophore (Enhanced yellow fluorescent protein-EYFP) is inverted and flanked by double LoxP sites (black and white triangles). After virus delivery in the brain, and in presence of cre-recombinase, the coding fragment is oriented in the right direction, allowing the expression of functional light-sensitive opsins in the ChAT+ neurons. (B) Schematic representation of virus delivery and opsin expression in ChAT-cre mice/rats. Rodents undergo surgery to infuse the adeno-associated virus (AAV) construct with the coding information for opsins and/or fluorophores. After 3 to 6 weeks rodents have sustained expression of the flourophore and/or excitatory (ChR2, ChIEF etc.) or inhibitory (halorhodopsin or arch 3.0) in ChAT+ cell soma and fibers. Left inset is a confocal micrograph of the basal forebrain of a ChAT-cre rat. Green cells in the top panel express EYFP as result of the AAV-floxed EYFP injection. Middle panel is a confocal micrograph of ChAT+ neurons, confirmed by the presence of anti-ChAT antibody staining. Bottom panel is a confocal micrograph indicating that the EYFP probe is expressed only in ChAT+ cells. Scale bar is $40 \mu \mathrm{m}$ (Luchicchi and Mansvelder, unpublished observations). Bottom inset confocal micrograph of EYFP+ labeled basal forebrain terminal fields within the mPFC (*pia; \# white matter). Scale bar is $200 \mu \mathrm{m}$ (Luchicchi and Mansvelder, unpublished observations). Figure is adapted from Jiang et al. (submitted). diffuse cholinergic inputs, that enable the cholinergic system to manipulate neocortical processing on a millisecond time scale as well as on slower time scales (Arroyo et al., 2012, 2014; Kimura et al., 2014).

On a network level, BF stimulation in anesthetized animals results in a desynchronized state of field potentials (Goard and Dan, 2009; Kalmbach et al., 2012; reviewed in Bloem et al., 2014) and neuronal firing in the $\mathrm{BF}$ is correlated with a reduction in low frequency, and an increase of high frequency, oscillations in the cortex (Duque et al., 2000; Manns et al., 2000). Since the frequency band activity is related to the state of arousal and the extent of cortical activation (Uhlhaas et al., 2008; Wang, 2010; Deco and Thiele, 2011; Cachope et al., 2012), this supports the idea that $\mathrm{ACh}$ acts as a neuromodulator involved in setting the state of arousal. Mechanistically, it was shown that ACh activated mAChRs on cortical pyramidal neurons (Gulledge et al., 2009), thereby shifting firing modes from bursting to tonic and changing low frequency high amplitude oscillatory activity to high frequency low amplitude activity on a network level (Metherate et al., 1992).

Other studies have looked at the effect of ACh on the direction of the flow of information in the cortex. Again, these studies have been performed in sensory areas because in these regions, neuronal responses could be related to sensory stimulation. In this regard it is reasonably well established that ACh is directly involved in the enhancement of feed-forward thalamic input into the sensory cortical areas (see Bloem et al., 2014, for a review). In L4 of visual cortex, ACh increases the gain and reliability 
of neuronal responses (Goard and Dan, 2009; Soma et al., 2012, 2013), an effect that is mediated by heteromeric nAChRs (Roberts et al., 2005; Disney et al., 2007). A similar effect of ACh is observed in the barrel cortex (Oldford and Castro-Alamancos, 2003).

In $\mathrm{L} 2 / 3$, the picture is more complex. In general, cholinergic modulation reduces firing rate in these layers by increasing GABAergic inhibition through mAChRs and nAChRs (Disney et al., 2012; Alitto and Dan, 2013; Soma et al., 2013; Kimura et al., 2014). The ACh modulation in firing rates was associated with enhancement of the reliability of encoding and modulation by stimuli presented (Goard and Dan, 2009; Soma et al., 2013).

The cortical depression associated with whisker trimming is accompanied by an increase of heteromeric nAChRs on interneurons in $\mathrm{L} 2 / 3$ and blockade of these $\mathrm{nAChRs}$ can prevent the cortical depression. These observations support the contention that heteromeric $n A C h R s$ in $\mathrm{L} 2 / 3$ are required for regulating the input- dependent responsiveness of the somatosensory cortex (Brown et al., 2012a).

Intra-cortical projections that connect superficial layers between different cortical columns are also inhibited by ACh through activation of mAChRs (Kimura and Baughman, 1997). Based on this finding and the reduced activity in the superficial layers, it has been suggested that ACh reduces horizontal processing through cortico-cortical interactions (Hasselmo and Giocomo, 2006). Indeed it has been observed in slices, and in vivo animal experiments as well as in humans, that the spatial spread of excitation in response to stimuli is reduced in the presence of elevated levels of ACh (Kimura et al., 1999; Silver et al., 2008). Such a modulation of excitation could have a sharpening effect on tuning curves of receptive fields and on discrimination of sensory stimuli (Roberts et al., 2005; Thiele et al., 2012). The combined effects of ACh-e.g., reduction of lateral interactions and increased sensitivity to thalamic inputs, would be expected to increase network sensitivity to incoming information and enhance signal to noise. A similar selective gain-control effect of $\mathrm{ACh}$ is observed with enhanced attention (Briggs et al., 2013) and could be one of the core mechanisms through which ACh modulates selective attention (Hasselmo and Giocomo, 2006; Deco and Thiele, 2011; Hasselmo and Sarter, 2011).

The functional impact of ACh on the deeper L5 and 6 is less well understood. It is clear that deep layer pyramidal and interneurons are modulated by both nAChRs and mAChRs (Gulledge et al., 2007; Kassam et al., 2008; Poorthuis et al., 2013). ACh is associated with both response suppression and response facilitation, although the net effect of endogenous cholinergic signaling is not clear (Soma et al., 2013). In L1, most (if not all) interneurons contain $\alpha 7^{*}$ and /or non- $\alpha 7^{*}$ nAChRs (Christophe et al., 2002; Alitto and Dan, 2013). Since these neurons inhibit both L1-3 interneurons and L2/3 pyramidal cells, the effect of cholinergic L1 activation appears to be complex with both net inhibition as well as disinhibition of pyramidal cells in deeper layers, and it is likely dependent on the source and extent of ACh release in L1 (Letzkus et al., 2011; Bennett et al., 2012; Cruikshank et al., 2012; Jiang et al., 2013; Arroyo et al., 2014).
Thalamic inputs to L5 neurons are strongly regulated by nicotinic receptor activation (Lambe et al., 2003; Couey et al., 2007; Poorthuis et al., 2013). Whether these are targeted by direct cholinergic inputs is not known. However, within the thalamic reticular nucleus, neurons receive biphasic fast cholinergic inputs mediated by non- $\alpha 7^{*}$ nAChRs and mAChRs (Sun et al., 2013).

\section{MANIPULATING THE CORTICAL CHOLINERGIC SYSTEM DURING BEHAVIOR}

Despite new insights as to how rapidly ACh levels may rise and fall in prefrontal cortex during cue detection (Sarter et al., 2014), there is still no direct demonstration of the cellular and synaptic mechanisms by which ACh controls attentional behaviors. Hints emerge from the optogenetic data on the disinhibitory circuit mechanisms in superficial layers of sensory areas (Letzkus et al., 2011; Arroyo et al., 2014), but the architecture of the somatosensory cortex differs substantially from that of prefrontal cortical regions. Indeed, L4 is absent from rodent medial PFC (Uylings et al., 2003), and projections from the mediodorsal thalamus target all layers of $\mathrm{mPFC}$, in contrast to the more discrete segregation of thalamo-cortical input seen in somatosensory areas (Douglas and Martin, 2004; Constantinople and Bruno, 2013). Few studies have appeared that manipulate the cholinergic system using optogenetics during cognitive tasks. In the primary visual cortex (V1) optogenetic stimulation of BF projections improved visual discrimination, a hallmark of visual attention, in a gono-go task (Pinto et al., 2013). Inhibiting the BF cholinergic projections to the visual cortex with either halo-rhodopsin (NpHR) or archaerhodopsin (Arch) impaired mouse performance on the same tasks (Pinto et al., 2013; Arroyo et al., 2014 for review).

In a recent report of unpublished observations, Sarter et al. (2014) optogenetically manipulated the excitability of BF projections to the PFC in mice performing a sustained attention task (SAT). This would be the first report of optogenetic manipulation of ACh release in the PFC and modulation of attention performance. Using ChAT-Cre mice expressing ChR2 in the BF, the authors report that brief blue light stimulation during cue presentation increases detection of the cue. Optogenetic stimulation of BF fibers in the absence of a cue, which predict the presentation of reward, results in a higher number of false-positive responses in cue detection of ChR2 mice. Inhibition of ACh fibers with NpHR stimulation reduced cue detection (Sarter et al., 2014). Previous studies from the same group have identified transient release of ACh in the mPFC as a modulator of cue-directed attention. In particular, fast ACh release occurred when the cue trial was preceded by an actual or perceived non-cue trial (Howe et al., 2013). Therefore, cholinergic transients may be involved in stateshifting: i.e., in regulating the shift from generalized monitoring to one of cue-directed attention (Sarter et al., 2014). In this sense, the optogenetic increase in false-positive responses, where the animal responds incorrectly to a non-cue trial, might reveal the mechanism by which transient release of ACh in the mPFC determines the transition from cue detection to a behavioral response. Full appreciation of the data underlying these conclusions awaits publication of the primary data referred to in the Sarter review (Sarter et al., 2014). 


\section{OPTOGENETIC CONTROL OF CHOLINERGIC PROJECTIONS TO HIPPOCAMPUS AND AMYGDALA: SYNAPTIC PLASTICITY AND OSCILLATIONS}

Hippocampal control over specific behaviors, such as learning and memory, is potently modulated by cholinergic signaling. Antagonists to both nicotinic and muscarinic AChRs impair performance in hippocampal-dependent memory tasks in rodents (Levin et al., 2002), as well as the ability to encode spatial information (Blokland et al., 1992). The majority of cholinergic inputs to the hippocampus (up to 90\%) come from the medial septum and diagonal band via the fimbria/fornix, and enter the hippocampus through the stratum oriens (SO; Frotscher and Léránth, 1985; Dutar et al., 1995). In addition, sparse cholinergic interneurons have been reported in some regions of the hippocampus, where they usually impinge on GABAergic interneurons (Griguoli and Cherubini, 2012). Both nicotinic and muscarinic AChRs are involved in regulating hippocampal network activity, such as synchronization of neuronal activity and altering of synaptic weights, thereby influencing hippocampal support of cognitive function (Yakel, 2012). Exogenous application of nicotinic agonists in hippocampal slices affects synaptic plasticity in nearly all hippocampal areas (Tu et al., 2009; Yakel, 2012), and muscarinic agonists induce fast network oscillations (Mann et al., 2005). However, it is still not completely clear how cholinergic receptors regulate rhythmic and phasic oscillations and synaptic plasticity in vivo, during hippocampal-dependent cognitive functions.

By stimulating septal cholinergic projecting neurons to the SO using both electrical and optogenetic methods, $\mathrm{Gu}$ and Yakel disentangled the temporal requirements for ACh release in the cholinergic modulation of synaptic strength of Schaffer's collateral (SC) to CA1 synapses (Gu and Yakel, 2011). With precisely timed activation of septal cholinergic neurons in ChAT-cre mice expressing ChR2, Yakel et al. showed that when the light-evoked increase of ACh release in the SO preceded the SC stimulation by $100 \mathrm{~ms}$, long-term potentiation (LTP) in the CA1 was triggered. This effect was dependent on the activation of $\alpha 7^{*} \mathrm{nAChRs}$ in postsynaptic neurons. On the other hand, ChR2 activation of cholinergic terminals only $10 \mathrm{~ms}$ before the SC stimulation resulted in hippocampal shortterm depression. In the latter case the effect was due to an $\alpha 7^{*}$ subunit-dependent inhibition of presynaptic glutamate release. Even more intriguing, the $\alpha 7^{*}$ component also altered synaptic plasticity when light pulses were delivered $10 \mathrm{~ms}$ after the SC activation. In fact, this latter protocol caused LTD in SO neurons by a mechanism which was attributed to $\mathrm{mAChR}$ activation, although whether the muscarinic component was pre- or postsynaptic is not clear (Gu and Yakel, 2011).

Muscarinic AChRs also modulate hippocampal activity by acting on interneurons (Bell et al., 2013). This is in line with the role of these receptors in orchestrating network oscillation within the hippocampus (Mann et al., 2005). Interestingly, interneuron network responses to light-evoked ACh release from the septum varied according to the level of cholinergic activity. In particular, low-intensity stimulation of cholinergic inputs was more likely to inhibit certain classes of interneurons via a mechanism dependent on the M4 type of mAChRs, whereas higher levels of ACh release triggered depolarization in other interneurons via broader muscarinic signaling. Cholinergic inputs from $\mathrm{BF}$ can also activate GABAergic interneurons through activation of $\alpha 4 \beta 2^{*}$ nAChRs in specific layers of the hippocampus (Bell et al., 2011).

Combining optogenetic stimulation of medial septum/diagonal band of Broca (MS/DBB) projections to the hippocampus with whole-cell patch clamp recordings and voltage sensitive dye (VSD) imaging it has been shown that inhibitory interneurons in the hippocampus receive cholinergic EPSPs in response to light stimulation of septal cholinergic fibers that are sensitive to Dh $\beta E$, but not MLA (Bell et al., 2011). These light-evoked EPSPs have slow kinetics similar to the non- $\alpha 7^{*}$ component seen in interneurons in the somatosensory cortex (Arroyo et al., 2012). The interneurons that express $\alpha 4 \beta 2 *$ have their somata or dendrites in the SO or stratum lacunosum-moleculare (SLM) of the hippocampus. Finally, another recent optogenetic study implicates ACh release from the MS/DBB in the modulation of synaptic plasticity triggered by GABAergic interneurons of the stratum oriens lacunosummaculare (OLM) in the SC-CA1 (Leão et al., 2012). Taken together, these data show that ACh inputs from the septum can influence hippocampal oscillations and plasticity in a highly specialized manner, resulting in a fine-tuning of hippocampal network activity in a layer specific manner and with millisecond timing. We still lack knowledge on the exact timing of activation of hippocampal cholinergic inputs during behavior. This will require both optogenetic manipulation of cholinergic projections, and concurrent visualization of activity of the BF projections in the hippocampus of awake-behaving animals.

Recently, optogenetic studies have been carried out to study the influence of other neuromodulatory systems interacting with cholinergic signaling to modulate hippocampal network activity. A set of studies conducted by Alger's group have very elegantly demonstrated that both the endocannabinoid (eCb) and endogenous opioid systems may participate in the generation of ACh-dependent modulation of hippocampal oscillatory activity (Nagode et al., 2011, 2014). With brief stimulation of the MS/DBB fibers in the CA1, Nagode et al. (2011) reported rhythmic inhibitory post-synaptic currents (IPSCs) in pyramidal neurons, accompanied by low frequency oscillation in hippocampal slices. Interestingly, the IPSCs, which were likely evoked by interneurons impinging on the pyramidal cells, were abolished by either GABA or mAChR antagonists. Moreover, the same events were also eCbsensitive, supporting the presence of active cannabinoid receptor (CB-R1) in the presynaptic interneuron terminal. It is widely known that $\mathrm{CB}-\mathrm{Rs}$ are expressed in the hippocampus, where they drive different forms of plasticity and mediate aspects of neuroprotection (Wilson and Nicoll, 2001). Only cholecystokinin $(\mathrm{CCK})+$ interneurons in hippocampus have functional CB1-Rs; CB-Rs are not present on PV+ interneurons (Katona et al., 1999). For this reason, it is likely that the cholinergic modulation of low frequency oscillations observed in this study depends solely on CCK+ cell activity. Optogenetic inhibition of either PV+ interneurons or glutamic-acid decarboxylase-2 (GAD2)+ cells in the CA1 confirmed that the PV- population of GABAergic interneurons were required for ACh induction of low frequency oscillations. Surprisingly the ability of these PV- cells to trigger 
low frequency rhythms in the hippocampus was blocked by a muopioid receptor antagonist, and subsequent induction of IPSCs in pyramidal neurons by ACh release in ChAT-Cre mice was shown to be sensitive to both CB1 and mu-receptor blockade (Nagode et al., 2014). Overall, these studies provide new insights on the possible cross-communication between the $\mathrm{eCb}$ and cholinergic modulatory systems in the regulation of hippocampal network activity and perhaps, in memory functions.

The effects of cholinergic input in general, and of nAChRs in particular, in the basolateral amygdala is also under study with optogenetic labeling of the neurons and projections of the nucleus basalis (Role, 2014). These studies have revealed that cholinergic signaling potently modulates the plasticity of cortical synapses on basolateral amygdale (BLA) pyramidal neurons, decreasing the threshold for induction of LTP. Excitatory effects of nucleus basalis stimulation on BLA firing is confirmed in in vivo recording and, most striking, the rate of extinction of responses to a cueassociated fear conditioning paradigm is slowed by brief optogenetic activation of the cholinergic terminal fields in BLA during training (Role, 2014). These findings are consistent with the idea that cholinergic signaling reinforces amygdala-based memories, perhaps rendering them less susceptible to subsequent extinction (Role, 2014).

\section{MODULATION OF STRIATAL CIRCUITS BY ACH CHOLINERGIC INTERNEURONS MODULATE THE RELEASE OF MULTIPLE STRIATAL NEUROTRANSMITTERS}

In addition to the robust modulatory activities of cholinergic signaling in cortex and hippocampus ACh is renowned for its strong regulatory role in subcortical brain regions within the midbrain and striatum. In particular, the core of the brain reward circuitry, comprising the ventral tegmental area (VTA) and the nucleus accumbens (NAc), is strongly modulated by ACh. The main source of ACh to the VTA neurons in the midbrain arises from the brainstem structures LDTg and PPTg, which play a role in acquisition of reward, and reward-related locomotor activity (Corrigall et al., 2002; Champtiaux et al., 2006). The main source of ACh for the NAc/ventral striatum, as well as for the dorsal striatum, is the cholinergic interneurons which comprise less than 2$5 \%$ of the total striatal neuron population (Descarries et al., 1997). Notwithstanding the paucity of striatal cholinergic interneurons, ACh signaling is directly involved in the modulation of (1) striatal dopamine (DA) release (Rice and Cragg, 2004; Exley and Cragg, 2008; Wang et al., 2014); (2) local network functionality (Galarraga et al., 1999; Koós and Tepper, 2002); and (3) striataldependent behaviors related to reward (Joshua et al., 2008).

The release of DA in striatum is crucial for functions such as motivation, reward and locomotor activity (see Cachope and Cheer, 2014, for a recent review) and cholinergic transmission can drive striatal DA release (Exley and Cragg, 2008). A recent study showed that selective optogenetic activation of accumbal cholinergic interneurons is sufficient to trigger DA release in the same region, and that this effect is independent of the suprathreshold activation of VTA DA neurons per se (Cachope et al., 2012; Threlfell et al., 2012; Wang et al., 2014). As such, the activity of cholinergic interneurons might boost the release of DA to encode aspects of reward-related events. This proposal is in line with studies in which photostimulation of cholinergic interneurons drove striatal DA release via activation of presynaptic nAChRs (Threlfell et al., 2012; Wang et al., 2014). On the other hand, Cachope et al. (2012) reported that the direct effect of cholinergic interneuron activation on DA release was only partially mediated by activation of AChRs. Combining optogenetic manipulation with in vitro pharmacology, revealed the collaboration of both nicotinic $\left(\beta 2^{*}\right)$ and muscarinic receptors, together with the activation of $\alpha$-amino-3-hydroxy-5-methyl-4isoxazolepropionic acid (AMPA)-type glutamate receptors in the enhancement of striatal DA release. Thus, a synergy exists between $\mathrm{ACh}$ and glutamate in modulating the activity of the striatal network. The source of glutamate may be the striatal cholinergic interneurons themselves (Gras et al., 2008). Activating ChR2 in cholinergic striatal interneurons triggers postsynaptic responses onto medium spiny neurons (MSNs), the most abundant striatal cell type. Under the stimulation conditions used by Higley et al., the direct postsynaptic responses were blocked by glutamate receptor antagonists alone and were insensitive to AChR blockade (Higley et al., 2011). This suggests that at low levels of stimulation direct control of MSN firing by "cholinergic" interneurons may also rely on fast glutamatergic transmission.

A follow-up of this study was conducted looking at the connections between ACh interneurons and other local interneurons. including the PV+ interneurons, that also contact MSNs directly (Koós and Tepper, 1999; Gittis et al., 2010). Activating dorsal striatal ACh interneurons triggers the co-release of ACh and glutamate on PV+ interneurons, activating slow non- $\alpha 7^{*} \mathrm{nAChR}$ currents, and both AMPA and N-methyl-D-aspartate (NMDA) receptors (Nelson et al., 2014). ACh and glutamate co-release was dependent on the presence of the vesicular glutamate transporter VGLUT3. This transporter is also involved in enhancing the vesicular loading of ACh and is important for di-synaptic inhibition of MSNs after PV+ excitation, a common feature in striatal information processing (Gras et al., 2008).

Activation of ChR2 in cholinergic interneurons in striatum also triggered GABA-A receptor-mediated postsynaptic currents in MSNs both in vivo and in vitro (Witten et al., 2010). Optogenetic stimulation of striatal cholinergic interneurons activated di-synaptic inhibitory responses in MSNs in vitro (Nelson et al., 2014). This effect was still present when PV+ neurons were ablated leading the authors to suggest that the di-synaptic inhibition of MSNs might be mediated by GABA release from DA terminals, that are studded with $\beta 2^{*}$ nAChRs and targeted by cholinergic interneuronal projections. Thus, striatal network activity could be orchestrated by cholinergic interneurons through simultaneous regulation of DA and GABA release in the same striatal area.

\section{OPTOGENETIC STUDIES OF ROLE OF CHOLINERGIC INTERNEURONS IN STRIATAL-DEPENDENT BEHAVIORS}

Optogenetic studies have helped to define the role of striatal cholinergic interneurons in multiple aspects of motor control, associative learning and reward (see Jiang et al., 2014, for review; Exley and Cragg, 2008). During reward-related events, cholinergic interneurons initially increase their firing activity, and then pause, after which they start firing in a third phase of 
elevated activity (e.g., Morris et al., 2004). Most likely, these phasic activity periods support DA release from VTA projections, with the $\mathrm{nAChR}$ mediated component being independent of VTA action potential firing (e.g., see Wang et al., 2014). By combining pharmacological, optogenetic and electrophysiological techniques, Straub et al. (2014) recently suggested reward coding resides in the pause in striatal ACh interneuron activity that results from the direct effect of nigrostriatal DA projections via D2 dopamine receptors on cholinergic interneurons. The authors did not identify which neurotransmitter is involved in the rebound phase. Other studies have suggested that the pause of ACh interneuron firing may be caused by a GABA component. Activating VTA GABA neurons that project to the striatum with ChR2 and recording activity on ACh interneurons resulted in a pause of ACh interneuron firing (Van Bockstaele and Pickel, 1995; Tan et al., 2012; Van Zessen et al., 2012). Interestingly this effect was only observed in striatal ACh interneurons, sparing the other cell population and it was insensitive to DA receptor blockade. Behavioral studies have confirmed that GABA mediated inhibition of cholinergic interneurons is a requisite component of stimulus-outcome association under relevant learning conditions, pinpointing the pivotal role of $\mathrm{ACh}$ interneurons in goal directed behaviors (Brown et al., 2012b). In addition, Witten et al. (2010) have reported that cholinergic interneuron silencing by $\mathrm{NpHR}$ stimulation reduced cocaine preference in behaving mice.

Taken together, these findings support the idea that cholinergic interneurons play a crucial role in the modulation of striatal activity, and striatal-dependent behavior. Recent anatomical studies have also underscored the potential importance of direct projections from the brainstem (PPTg and LDTg) to striatal cells (Dautan et al., 2014). Hence, it will be interesting to learn how cooperation between these different elements of the cholinergic system modulates striatal activity.

\section{SUMMARY AND CONCLUSIONS}

The application of optogenetic tools has accelerated the acquisition of precise information about the varied modulatory and direct synaptic signaling by $\mathrm{ACh}$ in an array of brain regions and behaviors. Selective expression of optogenetic probes in ChAT + neurons allows studies of the connectivity, functionality and anatomy of cholinergic neurons and circuits throughout the rodent brain (Atasoy et al., 2008; Witten et al., 2011; for reviews see: Arroyo et al., 2014; Jiang et al., 2014; Poorthuis et al., 2014). The application of these techniques has unveiled novel contributions of previously un-identified ChAT-positive neurons to activity-dependent proliferation and neurogenesis (PaezGonzalez et al., 2014) as well as implicating the co-storage-and perhaps co-release — of ACh and glutamate (e.g., see Higley et al., 2011). Many important challenges and new areas of exploration are now accessible to the cholinergic enthusiast. It will be particularly important to establish the precise mechanisms by which ACh modulates attention and contributes to top down executive control of directed behaviors. With the increasing number of research groups that have adopted the optogenetic toolbox, we can expect to learn more about these exciting topics in the not-so-distant future.

\section{ACKNOWLEDGMENTS}

Huibert D. Mansvelder received funding from the ERC StG "BrainSignals", the Dutch Fund for Economic Structure Reinforcement (FES, 0908 "NeuroBasic PharmaPhenomics project"), EU 7th Framework Programme (HEALTH-F2-2009242167 "SynSys") and an NWO VICI grant. Lorna W. Role is the recipient of an NIH Directors Pioneer Award and was supported by NS22061. We thank Dr. Floris Wouterlood for help with immunostaining and confocal microscopy for images shown in the Figure 1 and Dr. D. Talmage for critique of the manuscript.

\section{REFERENCES}

Alitto, H. J., and Dan, Y. (2013). Cell-type-specific modulation of neocortical activity by basal forebrain input. Front. Syst. Neurosci. 6:79. doi: 10.3389/fnsys. 2012.00079

Arroyo, S., Bennett, C., Aziz, D., Brown, S. P., and Hestrin, S. (2012). Prolonged disynaptic inhibition in the cortex mediated by slow, non- $\alpha 7$ nicotinic excitation of a specific subset of cortical interneurons. J. Neurosci. 32, 3859-3864. doi: 10. 1523/JNEUROSCI.0115-12.2012

Arroyo, S., Bennett, C., and Hestrin, S. (2014). Nicotinic modulation of cortical circuits. Front. Neural Circuits 8:30. doi: 10.3389/fncir.2014.00030

Atasoy, D., Aponte, Y., Su, H. H., and Sternson, S. M. (2008). A FLEX switch targets channelrhodopsin-2 to multiple cell types for imaging and long-range circuit mapping. J. Neurosci. 28, 7025-7030. doi: 10.1523/jneurosci.1954-08. 2008

Bell, L. A., Bell, K. A., and McQuiston, A. R. (2013). Synaptic muscarinic response types in hippocampal CA1 interneurons depend on different levels of presynaptic activity and different muscarinic receptor subtypes. Neuropharmacology 73 , 160-173. doi: 10.1016/j.neuropharm.2013.05.026

Bell, K. A., Shim, H., Chen, C. K., and McQuiston, A. R. (2011). Nicotinic excitatory postsynaptic potentials in hippocampal CAl interneurons are predominantly mediated by nicotinic receptors that contain $\alpha 4$ and $\beta 2$ subunits. Neuropharmacology 61, 1379-1388. doi: 10.1016/j.neuropharm.2011. 08.024

Bennett, C., Arroyo, S., Berns, D., and Hestrin, S. (2012). Mechanisms generating dual-component nicotinic EPSCs in cortical interneurons. J. Neurosci. 32, 17287-17296. doi: 10.1523/jneurosci.3565-12.2012

Bloem, B., Poorthuis, R. B., and Mansvelder, H. D. (2014). Cholinergic modulation of the medial prefrontal cortex: the role of nicotinic receptors in attention and regulation of neuronal activity. Front. Neural Circuits 8:17. doi: 10.3389/fncir. 2014.00017

Blokland, A., Honig, W., and Raaijmakers, W. G. M. (1992). Effects of intrahippocampal scopolamine injections in a repeated spatial acquisition task in the rat. Psychopharmacology (Berl) 109, 373-376. doi: 10.1007/bf022 45886

Briggs, F., Mangun, G. R., and Usrey, W. M. (2013). Attention enhances synaptic efficacy and the signal-to-noise ratio in neural circuits. Nature 499, 476-480. doi: 10.1038/nature12276

Brown, C. E., Sweetnam, D., Beange, M., Nahirney, P. C., and Nashmi, R. (2012a). $\alpha 4^{*}$ nicotinic acetylcholine receptors modulate experience-based cortical depression in the adult mouse somatosensory cortex. J. Neurosci. 32, 12071219. doi: 10.1523/JNEUROSCI.4568-11.2012

Brown, M. T. C., Tan, K. R., O’Connor, E. C., Nikonenko, I., Muller, D., and Lüscher, C. (2012b). Ventral tegmental area GABA projections pause accumbal cholinergic interneurons to enhance associative learning. Nature 492, 452-456. doi: 10.1038/nature11657

Cachope, R., and Cheer, J. F. (2014). Local control of striatal dopamine release. Front. Behav. Neurosci. 8:188. doi: 10.3389/fnbeh.2014.00188

Cachope, R., Mateo, Y., Mathur, B. N., Irving, J., Wang, H. L., Morales, M., et al. (2012). Selective activation of cholinergic interneurons enhances accumbal phasic dopamine release: setting the tone for reward processing. Cell Rep. 2, 3341. doi: 10.1016/j.celrep.2012.05.011

Champtiaux, N., Kalivas, P. W., and Bardo, M. T. (2006). Contribution of dihydrobeta-erythroidine sensitive nicotinic acetylcholine receptors in the ventral tegmental area to cocaine-induced behavioral sensitization in rats. Behav. Brain Res. 168, 120-126. doi: 10.1016/j.bbr.2005.10.017 
Changeux, J.-P. (2010). Nicotine addiction and nicotinic receptors: lessons from genetically modified mice. Nat. Rev. Neurosci. 11, 389-401. doi: 10. 1038/nrn2849

Christophe, E., Roebuck, A., Staiger, J. F., Lavery, D. J., Charpak, S., and Audinat, E. (2002). Two types of nicotinic receptors mediate an excitation of neocortical layer I interneurons. J. Neurophysiol. 88, 1318-1327. doi: 10.1152/jn.00199.2002

Constantinople, C. M., and Bruno, R. M. (2013). Deep cortical layers are activated directly by thalamus. Science 340, 1591-1594. doi: 10.1126/science.1236425

Corrigall, W. A., Coen, K. M., Zhang, J., and Adamson, L. K. (2002). Pharmacological manipulations of the pedunculopontine tegmental nucleus in the rat reduce self-administration of both nicotine and cocaine. Psychopharmacology (Berl) 160, 198-205. doi: 10.1007/s00213-001-0965-2

Couey, J. J., Meredith, R. M., Spijker, S., Poorthuis, R. B., Smit, A. B., Brussaard, A. B., et al. (2007). Distributed network actions by nicotine increase the threshold for spike-timing-dependent plasticity in prefrontal cortex. Neuron 54, 73-87. doi: 10.1016/j.neuron.2007.03.006

Court, J., Martin-Ruiz, C., Piggott, M., Spurden, D., Griffiths, M., and Perry, E. (2001). Nicotinic receptor abnormalities in Alzheimer's disease. Biol. Psychiatry 49, 175-184. doi: 10.1016/s0006-3223(00)01116-1

Cruikshank, S. J., Ahmed, O. J., Stevens, T. R., Patrick, S. L., Gonzalez, A. N., Elmaleh, M., et al. (2012). Thalamic control of layer 1 circuits in prefrontal cortex. J. Neurosci. 32, 17813-17823. doi: 10.1523/JNEUROSCI.3231-12.2012

Dani, J. A., and Harris, R. A. (2005). Nicotine addiction and comorbidity with alcohol abuse and mental illness. Nat. Neurosci. 8, 1465-1470. doi: 10.1038/nn1580

Dautan, D., Huerta-Ocampo, I., Witten, I. B., Deisseroth, K., Bolam, J. P., Gerdjikov, T., et al. (2014). A major external source of cholinergic innervation of the striatum and nucleus accumbens originates in the brainstem. J. Neurosci. 34, 4509-4518. doi: 10.1523/jneurosci.5071-13.2014

Deco, G., and Thiele, A. (2011). Cholinergic control of cortical network interactions enables feedback-mediated attentional modulation. Eur. J. Neurosci. 34, 146-157. doi: 10.1111/j.1460-9568.2011.07749.x

Deisseroth, K. (2011). Optogenetics. Nat. Methods 8, 26-29. doi: 10.1038/nmeth.f. 324

Descarries, L., Gisiger, V., and Steriade, M. (1997). Diffuse transmission by acetylcholine in the CNS. Prog. Neurobiol. 53, 603-625. doi: 10.1016/s03010082(97)00050-6

Disney, A. A., Aoki, C., and Hawken, M. J. (2007). Gain modulation by nicotine in macaque V1. Neuron 56, 701-713. doi: 10.1016/j.neuron.2007.09.034

Disney, A. A., Aoki, C., and Hawken, M. J. (2012). Cholinergic suppression of visual responses in primate V1 is mediated by GABAergic inhibition. J. Neurophysiol. 108, 1907-1923. doi: 10.1152/jn.00188.2012

Douglas, R. J., and Martin, K. A. C. (2004). Neuronal circuits of the neocortex. Annu. Rev. Neurosci. 27, 419-451. doi: 10.1146/annurev.neuro.27.070203. 144152

Duque, A., Balatoni, B., Detari, L., and Zaborszky, L. (2000). EEG correlation of the discharge properties of identified neurons in the basal forebrain. J. Neurophysiol. 84, 1627-1635.

Dutar, P., Bassant, M. H., Senut, M. C., and Lamour, Y. (1995). The septohippocampal pathway: structure and function of a central cholinergic system. Physiol. Rev. 75, 393-427.

Exley, R., and Cragg, S. J. (2008). Presynaptic nicotinic receptors: a dynamic and diverse cholinergic filter of striatal dopamine neurotransmission. $\mathrm{Br} . \mathrm{J}$. Pharmacol. 153(Suppl. 1), S283-S297. doi: 10.1038/sj.bjp.0707510

Frotscher, M., and Léránth, C. (1985). Cholinergic innervation of the rat hippocampus as revealed by choline acetyltransferase immunocytochemistry: a combined light and electron microscopic study. J. Comp. Neurol. 239, 237-246. doi: 10.1002/cne.902390210

Galarraga, E., Hernández-López, S., Reyes, A., Miranda, I., Bermudez-Rattoni, F., Vilchis, C., et al. (1999). Cholinergic modulation of neostriatal output: a functional antagonism between different types of muscarinic receptors. $J$. Neurosci. 19, 3629-3638.

Gittis, A. H., Nelson, A. B., Thwin, M. T., Palop, J. J., and Kreitzer, A. C. (2010). Distinct roles of GABAergic interneurons in the regulation of striatal output pathways. J. Neurosci. 30, 2223-2234. doi: 10.1523/jneurosci.487009.2010

Goard, M., and Dan, Y. (2009). Basal forebrain activation enhances cortical coding of natural scenes. Nat. Neurosci. 12, 1444-1449. doi: 10.1038/nn.2402

Gotti, C., and Clementi, F. (2004). Neuronal nicotinic receptors: from structure to pathology. Prog. Neurobiol. 74, 363-396. doi: 10.1016/j.pneurobio.2004.09.006
Gras, C., Amilhon, B., Lepicard, E. M., Poirel, O., Vinatier, J., Herbin, M., et al. (2008). The vesicular glutamate transporter VGLUT3 synergizes striatal acetylcholine tone. Nat. Neurosci. 11, 292-300. doi: 10.1038/nn2052

Griguoli, M., and Cherubini, E. (2012). Regulation of hippocampal inhibitory circuits by nicotinic acetylcholine receptors. J. Physiol. 590, 655-666. doi: 10. 1113/jphysiol.2011.220095

Gu, Z., and Yakel, J. L. (2011). Timing-dependent septal cholinergic induction of dynamic hippocampal synaptic plasticity. Neuron 71, 155-165. doi: 10.1016/j. neuron.2011.04.026

Gulledge, A. T., Bucci, D. J., Zhang, S. S., Matsui, M., and Yeh, H. H. (2009). M1 receptors mediate cholinergic modulation of excitability in neocortical pyramidal neurons. J. Neurosci. 29, 9888-9902. doi: 10.1523/jneurosci.1366-09. 2009

Gulledge, A. T., Park, S. B., Kawaguchi, Y., and Stuart, G. J. (2007). Heterogeneity of phasic cholinergic signaling in neocortical neurons. J. Neurophysiol. 97, 22152229. doi: 10.1152/jn.00493.2006

Hasselmo, M. E., and Giocomo, L. M. (2006). Cholinergic modulation of cortical function. J. Mol. Neurosci. 30, 133-136. doi: 10.1385/JMN:30:1:133

Hasselmo, M. E., and Sarter, M. (2011). Modes and models of forebrain cholinergic neuromodulation of cognition. Neuropsychopharmacology 36, 52-73. doi: 10 . 1038/npp.2010.104

Higley, M. J., Gittis, A. H., Oldenburg, I. A., Balthasar, N., Seal, R. P., Edwards, R. H., et al. (2011). Cholinergic interneurons mediate fast VGluT3-dependent glutamatergic transmission in the striatum. PLoS One 6:e19155. doi: 10 1371/journal.pone.0019155

Howe, W. M., Berry, A. S., Francois, J., Gilmour, G., Carp, J. M., Tricklebank, M., et al. (2013). Prefrontal cholinergic mechanisms instigating shifts from monitoring for cues to cue-guided performance: converging electrochemical and fMRI evidence from rats and humans. J. Neurosci. 33, 8742-8752. doi: 10. 1523/jneurosci.5809-12.2013

Huang, Z. J., and Zeng, H. (2013). Genetic approaches to neural circuits in the mouse. Annu. Rev. Neurosci. 36, 183-215. doi: 10.1146/annurev-neuro-062012170307

Jiang, L., López-Hernández, G. Y., Lederman, J., Talmage, D. A., and Role, W. L. (2014). Optogenetic studies of nicotinic contributions to cholinergic signaling in the central nervous system. Rev. Neurosci. doi: 10.1515/revneuro-2014-0032. [Epub ahead of print].

Jiang, X., Wang, G., Lee, A. J., Stornetta, R. L., and Zhu, J. J. (2013). The organization of two new cortical interneuronal circuits. Nat. Neurosci. 16, 210 218. doi: $10.1038 / \mathrm{nn} .3305$

Joshua, M., Adler, A., Mitelman, R., Vaadia, E., and Bergman, H. (2008). Midbrain dopaminergic neurons and striatal cholinergic interneurons encode the difference between reward and aversive events at different epochs of probabilistic classical conditioning trials. J. Neurosci. 28, 11673-11684. doi: 10.1523/jneurosci. 3839-08.2008

Kalmbach, A., Hedrick, T., and Waters, J. (2012). Selective optogenetic stimulation of cholinergic axons in neocortex. J. Neurophysiol. 107, 2008-2019. doi: 10. 1152/jn.00870.2011

Kassam, S. M., Herman, P. M., Goodfellow, N. M., Alves, N. C., and Lambe, E. K. (2008). Developmental excitation of corticothalamic neurons by nicotinic acetylcholine receptors. J. Neurosci. 28, 8756-8764. doi: 10.1523/JNEUROSCI. 2645-08.2008

Katona, I., Sperlágh, B., Sík, A., Käfalvi, A., Vizi, E. S., Mackie, K., et al. (1999). Presynaptically located CB1 cannabinoid receptors regulate GABA release from axon terminals of specific hippocampal interneurons. J. Neurosci. 19, 45444558.

Kawai, H., Lazar, R., and Metherate, R. (2007). Nicotinic control of axon excitability regulates thalamocortical transmission. Nat. Neurosci. 10, 1168-1175. doi: 10. 1038/nn 1956

Kilgard, M. P., and Merzenich, M. M. (1998). Cortical map reorganization enabled by nucleus basalis activity. Science 279, 1714-1718. doi: 10.1126/science.279. 5357.1714

Kimura, F., and Baughman, R. W. (1997). Distinct muscarinic receptor subtypes suppress excitatory and inhibitory synaptic responses in cortical neurons. $J$. Neurophysiol. 77, 709-716.

Kimura, F., Fukuda, M., and Tsumoto, T. (1999). Acetylcholine suppresses the spread of excitation in the visual cortex revealed by optical recording: possible differential effect depending on the source of input. Eur. J. Neurosci. 11, 35973609. doi: 10.1046/j.1460-9568.1999.00779.x 
Kimura, R., Safari, M.-S., Mirnajafi-Zadeh, J., Kimura, R., Ebina, T., Yanagawa, Y., et al. (2014). Curtailing effect of awakening on visual responses of cortical neurons by cholinergic activation of inhibitory circuits. J. Neurosci. 34, 1012210133. doi: 10.1523/jneurosci.0863-14.2014

Klinkenberg, I., Sambeth, A., and Blokland, A. (2011). Acetylcholine and attention. Behav. Brain Res. 221, 430-442. doi: 10.1016/j.bbr.2010.11.033

Koós, T., and Tepper, J. M. (1999). Inhibitory control of neostriatal projection neurons by GABAergic interneurons. Nat. Neurosci. 2, 467-472. doi: 10.1038/ 8138

Koós, T., and Tepper, J. M. (2002). Dual cholinergic control of fast-spiking interneurons in the neostriatum. J. Neurosci. 22, 529-535.

Lambe, E. K., Picciotto, M. R., and Aghajanian, G. K. (2003). Nicotine induces glutamate release from thalamocortical terminals in prefrontal cortex. Neuropsychopharmacology 28, 216-225. doi: 10.1038/sj.npp.1300032

Leão, R. N., Mikulovic, S., Leão, K. E., Munguba, H., Gezelius, H., Enjin, A., et al. (2012). OLM interneurons differentially modulate CA3 and entorhinal inputs to hippocampal CA1 neurons. Nat. Neurosci. 15, 1524-1530. doi: 10.1038/nn. 3235

Leslie, F. M., Mojica, C. Y., and Reynaga, D. D. (2013). Nicotinic receptors in addiction pathways. Mol. Pharmacol. 83, 753-758. doi: 10.1124/mol.112. 083659

Letzkus, J. J., Wolff, S. B. E., Meyer, E. M. M., Tovote, P., Courtin, J., Herry, C., et al. (2011). A disinhibitory microcircuit for associative fear learning in the auditory cortex. Nature 480, 331-335. doi: 10.1038/nature10674

Levin, E. D., Bradley, A., Addy, N., and Sigurani, N. (2002). Hippocampal alpha 7 and alpha 4 beta 2 nicotinic receptors and working memory. Neuroscience 109, 757-765. doi: 10.1016/s0306-4522(01)00538-3

Mann, E. O., Suckling, J. M., Hajos, N., Greenfield, S. A., and Paulsen, O. (2005). Perisomatic feedback inhibition underlies cholinergically induced fast network oscillations in the rat hippocampus in vitro. Neuron 45, 105-117. doi: 10.1016/j. neuron.2004.12.016

Manns, I. D., Alonso, A., and Jones, B. E. (2000). Discharge profiles of juxtacellularly labeled and immunohistochemically identified GABAergic basal forebrain neurons recorded in association with the electroencephalogram in anesthetized rats. J. Neurosci. 20, 9252-9263.

Martin, L. F., and Freedman, R. (2007). Schizophrenia and the alpha7 nicotinic acetylcholine receptor. Int. Rev. Neurobiol. 78, 225-246. doi: 10.1016/S00747742(06)78008-4

Mesulam, M. M. (1995). Cholinergic pathways and the ascending reticular activating system of the human brain. Ann. N Y Acad. Sci. 757, 169-179. doi: 10.1111/j. 1749-6632.1995.tb17472.x

Metherate, R., Cox, C. L., and Ashe, J. H. (1992). Cellular bases of neocortical activation: modulation of neural oscillations by the nucleus basalis and endogenous acetylcholine. J. Neurosci. 12, 4701-4711.

Morris, G., Arkadir, D., Nevet, A., Vaadia, E., and Bergman, H. (2004). Coincident but distinct messages of midbrain dopamine and striatal tonically active neurons. Neuron 43, 133-143. doi: 10.1016/j.neuron.2004.06.012

Nagode, D. A., Tang, A. H., Karson, M. A., Klugmann, M., and Alger, B. E. (2011). Optogenetic release of ACh induces rhythmic bursts of perisomatic IPSCs in hippocampus. PLoS One 6:e27691. doi: 10.1371/journal.pone. 0027691

Nagode, D. A., Tang, A.-H., Yang, K., and Alger, B. E. (2014). Optogenetic identification of an intrinsic cholinergically driven inhibitory oscillator sensitive to cannabinoids and opioids in hippocampal CA1. J. Physiol. 592, 103-123. doi: 10. 1113/jphysiol.2013.257428

Nelson, A. B., Hammack, N., Yang, C. F., Shah, N. M., Seal, R. P., and Kreitzer, A. C. (2014). Striatal cholinergic interneurons drive GABA release from dopamine terminals. Neuron 82, 63-70. doi: 10.1016/j.neuron.2014. 01.023

Oldford, E., and Castro-Alamancos, M. A. (2003). Input-specific effects of acetylcholine on sensory and intracortical evoked responses in the "barrel cortex" in vivo. Neuroscience 117, 769-778. doi: 10.1016/s0306-4522(02)00663-2

Paez-Gonzalez, P., Asrican, B., Rodriguez, E., and Kuo, C. T. (2014). Identification of distinct ChAT(+) neurons and activity-dependent control of postnatal SVZ neurogenesis. Nat. Neurosci. 17, 934-942. doi: 10.1038/nn.3734

Parikh, V., Kozak, R., Martinez, V., and Sarter, M. (2007). Prefrontal acetylcholine release controls cue detection on multiple timescales. Neuron 56, 141-154. doi: 10.1016/j.neuron.2007.08.025
Parikh, V., and Sarter, M. (2008). Cholinergic mediation of attention. Ann. NY Acad. Sci. 1129, 225-235. doi: 10.1196/annals.1417.021

Passetti, F., Dalley, J. W., O'Connell, M. T., Everitt, B. J., and Robbins, T. W. (2000). Increased acetylcholine release in the rat medial prefrontal cortex during performance of a visual attentional task. Eur. J. Neurosci. 12, 3051-3058. doi: 10. 1046/j.1460-9568.2000.00183.x

Picciotto, M. R., Higley, M. J., and Mineur, Y. S. (2012). Acetylcholine as a neuromodulator: cholinergic signaling shapes nervous system function and behavior. Neuron 76, 116-129. doi: 10.1016/j.neuron.2012.08.036

Pinto, L., Goard, M. J., Estandian, D., Xu, M., Kwan, A. C., Lee, S.-H., et al. (2013). Fast modulation of visual perception by basal forebrain cholinergic neurons. Nat. Neurosci. 16, 1857-1863. doi: 10.1038/nn.3552

Poorthuis, R. B., Bloem, B., Schak, B., Wester, J., de Kock, C. P. J., and Mansvelder, H. D. (2013). Layer-specific modulation of the prefrontal cortex by nicotinic acetylcholine receptors. Cereb. Cortex 23, 148-161. doi: 10.1093/cercor/ bhr390

Poorthuis, R. B., Enke, L., and Letzkus, J. J. (2014). Cholinergic circuit modulation through differential recruitment of neocortical interneuron types during behaviour. J. Physiol. 592, 4155-4164. doi: 10.1113/jphysiol.2014.273862

Ren, J., Qin, C., Hu, F., Tan, J., Qiu, L., Zhao, S., et al. (2011). Habenula “cholinergic" neurons corelease glutamate and acetylcholine and activate postsynaptic neurons via distinct transmission modes. Neuron 69, 445-452. doi: 10.1016/j. neuron.2010.12.038

Rice, M. E., and Cragg, S. J. (2004). Nicotine amplifies reward-related dopamine signals in striatum. Nat. Neurosci. 7, 583-584. doi: 10.1038/nn1244

Roberts, M. J., Zinke, W., Guo, K., Robertson, R., McDonald, J. S., and Thiele, A. (2005). Acetylcholine dynamically controls spatial integration in marmoset primary visual cortex. J. Neurophysiol. 93, 2062-2072. doi: 10.1152/jn.00911. 2004

Role, L. W. (2014). "Cholinergic modulation of cortical-amygdala circuits and behavior. ABS S25," in Nicotinic Acetylcholine Receptors, Wellcome Trust Scientific Conference, eds I. Bermudez, N. Millar and S. Wonnacott.

Sarter, M., Lustig, C., Howe, W. M., Gritton, H., and Berry, A. S. (2014). Deterministic functions of cortical acetylcholine. Eur. J. Neurosci. 39, 1912-1920. doi: 10. 1111/ejn. 12515

Sarter, M., Parikh, V., and Howe, W. M. (2009). Phasic acetylcholine release and the volume transmission hypothesis: time to move on. Nat. Rev. Neurosci. 10, 383-390. doi: 10.1038/nrn2635

Silver, M. A., Shenhav, A., and D'Esposito, M. (2008). Cholinergic enhancement reduces spatial spread of visual responses in human early visual cortex. Neuron 60, 904-914. doi: 10.1016/j.neuron.2008.09.038

Smiley, J. F., Morrell, F., and Mesulam, M. M. (1997). Cholinergic synapses in human cerebral cortex: an ultrastructural study in serial sections. Exp. Neurol. 144, 361-368. doi: 10.1006/exnr.1997.6413

Soma, S., Shimegi, S., Osaki, H., and Sato, H. (2012). Cholinergic modulation of response gain in the primary visual cortex of the macaque. J. Neurophysiol. 107, 283-291. doi: 10.1152/jn.00330.2011

Soma, S., Shimegi, S., Suematsu, N., Tamura, H., and Sato, H. (2013). Modulationspecific and laminar-dependent effects of acetylcholine on visual responses in the rat primary visual cortex. PLoS One 8:e68430. doi: 10.1371/journal.pone. 0068430

Straub, C., Tritsch, N. X., Hagan, N. A., Gu, C., and Sabatini, B. L. (2014). Multiphasic modulation of cholinergic interneurons by nigrostriatal afferents. J. Neurosci. 34, 8557-8569. doi: 10.1523/jneurosci.0589-14.2014

Sun, Y.-G., Pita-Almenar, J. D., Wu, C.-S., Renger, J. J., Uebele, V. N., Lu, H.-C., et al. (2013). Biphasic cholinergic synaptic transmission controls action potential activity in thalamic reticular nucleus neurons. J. Neurosci. 33, 2048-2059. doi: 10.1523/JNEUROSCI.3177-12.2013

Tan, K. R., Yvon, C., Turiault, M., Mirzabekov, J. J., Doehner, J., Labouèbe, G., et al. (2012). GABA neurons of the VTA drive conditioned place aversion. Neuron 73, 1173-1183. doi: 10.1016/j.neuron.2012.02.015

Thiele, A., Herrero, J. L., Distler, C., and Hoffmann, K.-P. (2012). Contribution of cholinergic and GABAergic mechanisms to direction tuning, discriminability, response reliability and neuronal rate correlations in macaque middle temporal area. J. Neurosci. 32, 16602-16615. doi: 10.1523/jneurosci.0554-12. 2012

Threlfell, S., Lalic, T., Platt, N. J., Jennings, K. A., Deisseroth, K., and Cragg, S. J. (2012). Striatal dopamine release is triggered by synchronized activity in 
cholinergic interneurons. Neuron 75, 58-64. doi: 10.1016/j.neuron.2012. 04.038

Tu, B., Gu, Z., Shen, J.-X., Lamb, P. W., and Yakel, J. L. (2009). Characterization of a nicotine-sensitive neuronal population in rat entorhinal cortex. J. Neurosci. 29, 10436-10448. doi: 10.1523/jneurosci.2580-09.2009

Turrini, P., Casu, M. A., Wong, T. P., De Koninck, Y., Ribeiro-da-Silva, A., and Cuello, A. C. (2001). Cholinergic nerve terminals establish classical synapses in the rat cerebral cortex: synaptic pattern and age-related atrophy. Neuroscience 105, 277-285. doi: 10.1016/s0306-4522(01)00172-5

Uhlhaas, P. J., Haenschel, C., Nikolić, D., and Singer, W. (2008). The role of oscillations and synchrony in cortical networks and their putative relevance for the pathophysiology of schizophrenia. Schizophr. Bull. 34, 927-943. doi: 10. 1093/schbul/sbn062

Uylings, H. B. M., Groenewegen, H. J., and Kolb, B. (2003). Do rats have a prefrontal cortex? Behav. Brain Res. 146, 3-17. doi: 10.1016/j.bbr.2003.09.028

Van Bockstaele, E. J., and Pickel, V. M. (1995). GABA-containing neurons in the ventral tegmental area project to the nucleus accumbens in rat brain. Brain Res. 682, 215-221. doi: 10.1016/0006-8993(95)00334-m

Van Zessen, R., Phillips, J. L., Budygin, E. A., and Stuber, G. D. (2012). Activation of VTA GABA neurons disrupts reward consumption. Neuron 73, 1184-1194. doi: 10.1016/j.neuron.2012.02.016

von Engelhardt, J., Eliava, M., Meyer, A. H., Rozov, A., and Monyer, H. (2007). Functional characterization of intrinsic cholinergic interneurons in the cortex. J. Neurosci. 27, 5633-5642. doi: 10.1523/jneurosci.4647-06.2007

Wang, X.-J. (2010). Neurophysiological and computational principles of cortical rhythms in cognition. Physiol. Rev. 90, 1195-1268. doi: 10.1152/physrev.00035. 2008

Wang, L., Shang, S., Kang, X., Teng, S., Zhu, F., Liu, B., et al. (2014). Modulation of dopamine release in the striatum by physiologically relevant levels of nicotine. Nat. Commun. 5:3925. doi: 10.1038/ncomms4925

Wess, J. (2003). Novel insights into muscarinic acetylcholine receptor function using gene targeting technology. Trends Pharmacol. Sci. 24, 414-420. doi: 10. 1016/s0165-6147(03)00195-0

Wilson, R. I., and Nicoll, R. A. (2001). Endogenous cannabinoids mediate retrograde signalling at hippocampal synapses. Nature 410, 588-592. doi: 10. $1038 / 35069076$
Witten, I. B., Lin, S.-C., Brodsky, M., Prakash, R., Diester, I., Anikeeva, P., et al. (2010). Cholinergic interneurons control local circuit activity and cocaine conditioning. Science 330, 1677-1681. doi: 10.1126/science.1193771

Witten, I. B., Steinberg, E. E., Lee, S. Y., Davidson, T. J., Zalocusky, K. A., Brodsky, M., et al. (2011). Recombinase-driver rat lines: tools, techniques and optogenetic application to dopamine-mediated reinforcement. Neuron 72, 721-733. doi: 10 . 1016/j.neuron.2011.10.028

Wonnacott, S. (1997). Presynaptic nicotinic ACh receptors. Trends Neurosci. 20, 92 98. doi: 10.1016/s0166-2236(96)10073-4

Woolf, N. J. (1991). Cholinergic systems in mammalian brain and spinal cord. Prog. Neurobiol. 37, 475-524. doi: 10.1016/0301-0082(91)90006-m

Yakel, J. L. (2012). Nicotinic ACh receptors in the hippocampus: role in excitability and plasticity. Nicotine Tob. Res. 14, 1249-1257. doi: 10.1093/ntr/nts091

Yizhar, O., Fenno, L. E., Davidson, T. J., Mogri, M., and Deisseroth, K. (2011). Optogenetics in neural systems. Neuron 71, 9-34. doi: 10.1016/j.neuron.2011. 06.004

Zaborszky, L., Pang, K., Somogyi, J., Nadasdy, Z., and Kallo, I. (1999). The basal forebrain corticopetal system revisited. Ann. N Y Acad. Sci. 877, 339-367. doi: 10. 1111/j.1749-6632.1999.tb09276.x

Conflict of Interest Statement: The authors declare that the research was conducted in the absence of any commercial or financial relationships that could be construed as a potential conflict of interest.

Received: 09 August 2014; accepted: 03 October 2014; published online: 27 October 2014.

Citation: Luchicchi A, Bloem B, Viaña JNM, Mansvelder HD and Role LW (2014) Illuminating the role of cholinergic signaling in circuits of attention and emotionally salient behaviors. Front. Synaptic Neurosci. 6:24. doi: 10.3389/fnsyn.2014.00024 This article was submitted to the journal Frontiers in Synaptic Neuroscience. Copyright (c) 2014 Luchicchi, Bloem, Viaña, Mansvelder and Role. This is an openaccess article distributed under the terms of the Creative Commons Attribution License (CC BY). The use, distribution and reproduction in other forums is permitted, provided the original author(s) or licensor are credited and that the original publication in this journal is cited, in accordance with accepted academic practice. No use, distribution or reproduction is permitted which does not comply with these terms. 